clinical trials of hypericum extract for different pharmaceutical companies. AD and MK are employees of Dr Willmar Schwabe Pharmaceuticals.

Ethical approval: The protocol was approved by the participating centres' appropriate independent ethics committees.

1 Linde K, Mulrow CD. St John's wort for depression. Cochrane Database Syst Rev 2004;(4):CD000448.

2 Harrer G, Hübner WD, Podzuweit H. Effectiveness and tolerance of the hypericum extract LI 160 compared to maprotiline: a multicenter double-blind study.J Geriatric Psychiatry Neurol 1994;7(suppl 1):S24-8.

3 Philipp M, Kohnen R, Hiller KO. Hypericum extract versus imipramine or placebo in patients with moderate depression: randomised multicentre study of treatment for eight weeks. BMJ 1999;319:1534-8.

4 Vorbach EU, Hübner WD, Arnoldt KH. Effectiveness and tolerance of the hypericum extract LI 160 in comparison with imipramine: randomized double-blind study with 135 outpatients. I Geriatric Psychiatry Neurol 1994;7(suppl 1):S19-23.

5 Wheatley D. LI 160, an extract of St. John's wort, versus amitriptyline in mildly to moderately depressed outpatients-a controlled 6-week clinical trial. Pharmacopsychiatry 1997;30(suppl 2):77-80.
6 Harrer G, Schmidt U, Kuhn U, Biller A. Äquivalenzvergleich Johanniskrautextrakt LoHyp-57 versus Fluoxetin. Arzneimittel-Forschung $1998 \cdot 49 \cdot 3-10$

7 Izzo AA. Drug interactions with St. John's Wort (Hypericum perforatum): a review of the clinical evidence. Int J Clin Pharmacol Ther 2004;42:139-48. Montgomery SA. Clinically relevant effect sizes in depression. Eur Neuropsychopharmacology 1994;4:283-4.

9 Committee for Proprietary Medicinal Products. Points to consider on switching between superiority and non-inferiority. London: European Agency for the Evaluation of Medicinal Products, 2000.

10 Paykel ES. The classification of depression. Br J Clin Pharmacol 1983;15(suppl 2):155-9S.

11 Hypericum Depression Trial Study Group. Effect of Hypericum perforatum (St. John's wort) in major depressive disorder. JAMA 2002;287: tum (St.

12 Dunner DL, Dunbar GC. Optimal dose regimen for paroxetine. J Clin Psychiatry 1992;53(suppl):21-6.

13 Bourin M, Chue P, Guillon Y. Paroxetine: a review. CNS Drug Rev 2001;7:25-47.

(Accepted 17 December 2004)

doi $10.1136 /$ bmj.38356.655266.82
South Manchester University Hospital, Manchester M23 9LT

Ben Bridgewater consultant surgeon

Correspondence to: B Bridgewater ben.bridgewater@ smuht.nwest.nhs.uk

BMJ 2005;330:506-10

\title{
Mortality data in adult cardiac surgery for named surgeons: retrospective examination of prospectively collected data on coronary artery surgery and aortic valve replacement
}

Ben Bridgewater on behalf of the adult cardiac surgeons of north west England

\begin{abstract}
Objectives To present named surgeon mortality for isolated first time coronary artery surgery and aortic valve surgery.

Design Retrospective analysis of prospectively collected data.

Setting All NHS hospitals undertaking adult cardiac surgery in north west England.

Participants 25 consultant surgeons carrying out coronary artery surgery and aortic valve replacement between April 2001 and March 2004.

Main outcome measures Mortality for both operations according to surgeon. EuroSCORE to stratify patients into low and high risk.

Results 10163 patients underwent surgery under 25 surgeons. The average number of patients per surgeon was 363 for coronary artery surgery and 44 for aortic valve replacement. Seventeen per cent of the patients undergoing coronary artery surgery and half of those undergoing aortic valve surgery were considered high risk. The average mortality was $1.8 \%$ (range $0-3.8 \%$ ) for coronary surgery and $1.9 \%$ $(0-12.5 \%)$ for aortic valve surgery. Mortality for all surgeons fell below $99 \%$ control limits of the national mean for both operations.

Conclusions The presented mortality figures for the two cardiac operations fell within accepted limits for all surgeons. The division of outcomes according to low and high risk patients is imperfect but may help to inform the public about the complexities of this type of analysis and prevent surgeons avoiding high risk patents who may benefit from an operation.
\end{abstract}

\section{Introduction}

Recent years have seen a move towards increased openness and transparency in healthcare delivery. This has been accelerated by a series of events, including the Bristol Royal Infirmary inquiry into paediatric cardiac surgery deaths. ${ }^{1}$ One recommendation of the inquiry was that patients must be able to see information about the relative performance of individual consultants operating within hospitals. The Society of Cardiothoracic Surgeons of Great Britain and Ireland therefore published a study in 2004 of activity and performance of all consultants undertaking adult cardiac surgery in the United Kingdom. ${ }^{2}$ The history leading to this analysis and the underlying methods have been comprehensively described. ${ }^{3}$ The study was conducted on a single operation: first time isolated coronary artery surgery. Because of a lack of comprehensive data on which to perform a complete analysis that would allow adjustments to be made for differing case mix, the benchmarking was done on "crude" non-adjusted mortality data. The exact mortality for individual surgeons was not given, but instead surgeons were listed with a comment about whether they met the Society of Cardiothoracic Surgeons standards, which were defined as being acceptable if the surgeon fell within $99.99 \%$ confidence intervals of the national average.

Janet Smith has commented that the General Medical Council could be criticised for putting the interests of doctors before the interests of patients. ${ }^{4}$ When it comes to publishing mortality data for individual surgeons there is potentially a conflict between the interests of these two groups and the confidence intervals used recently by the Society of Cardio- 
thoracic Surgeons have been criticised as leaning too far towards protecting the reputations of surgeons. ${ }^{5}$ To be useful to the public and fair to surgeons it is important that any analysis of surgeon specific data should give easily understood information that will be meaningful, be based on robust data, and compare "like with like." It is also essential that any such publication should not ultimately disadvantage patients by engendering a culture where surgeons are anxious to obtain good overall mortality results by turning down higher risk patients, ${ }^{2}{ }^{6}$ who often have the most to gain from successful surgery.

Recently the Freedom of Information Act has become law in England and Wales. This gives individuals the right to obtain data from public organisations. Under the act it is inevitable that individual surgeon data will come into the public domain. Some individual hospitals are responding by putting results on the internet. We feel that it is important that any such analysis should be comprehensive and well informed. We have collected a full dataset on all patients undergoing surgery in north west England since 1997 and can stratify for patient risk.

\section{Methods}

The north west quality improvement programme in cardiac interventions is a regional consortium involving all four NHS centres that perform cardiac surgery and percutaneous coronary interventions in adults in north west England. ${ }^{7}$ We have collected prospective data on all patients undergoing cardiac surgery since 1 April 1997, including preoperative and operative variables, to enable a predicted mortality to be calculated. Data were collected in each institution and returned to a central source for analysis. Validation of data was conducted in each centre. Mortality was defined as any postoperative death in hospital during the admission for surgery.

For this analysis we looked at all patients undergoing surgery between 1 April 2001 and 31 March 2004, including patients undergoing private surgery within the NHS hospitals but excluding waiting list initiative and private practice cases undertaken outside the NHS hospitals. For this analysis we have reported outcomes for isolated first time coronary artery surgery and isolated first time aortic valve surgery. To adjust for predicted risk we have used a well accepted risk prediction algorithm, the EuroSCORE. ${ }^{8}$ If a factor necessary to calculate the score was missing in a record, we assumed that factor to be absent (this occurred in less than $2 \%$ of cases). To present the data we have subdivided the cases into low risk (score $\leq 5)$ and high risk (score $\geq 6$ ) groups. ${ }^{9}{ }^{10}$ To compare mortality with national data we used funnel plots with exact (Clopper-Pearson) 99\% control limits. ${ }^{11}$ All analysis was performed with SAS for Windows version 8.2.

\section{Results}

Tables 1 and 2 present the results for the two operations. To make the tables easier to read we have not shown confidence intervals.

A total of 10163 patients had surgery under the care of 25 consultant surgeons. Each surgeon operated on an average of 363 patients (range 41-567) for coro-

Table 1 Outcome for isolated first time coronary artery bypass graft (CABG). Mortality for all surgeons falls below the $99 \%$ upper control limit of national mortality for crude data, and thus indicates satisfactory performance

\begin{tabular}{|c|c|c|c|c|c|c|c|c|c|}
\hline \multirow[b]{2}{*}{ Surgeon } & \multicolumn{3}{|c|}{ Low risk isolated CABG } & \multicolumn{3}{|c|}{ High risk isolated CABG } & \multicolumn{3}{|c|}{ All isolated CABG } \\
\hline & Cases & Deaths & $\%$ survival & Cases & Deaths & $\%$ survival & Cases & Deaths & $\%$ survival \\
\hline $\mathrm{Au}^{\star}$ & 349 & 1 & 99.7 & 76 & 4 & 94.7 & 425 & 5 & 98.8 \\
\hline Bridgewater† & 223 & 2 & 99.1 & 35 & 1 & 97.1 & 258 & 3 & 98.8 \\
\hline Campbell† & 248 & 2 & 99.2 & 42 & 3 & 92.9 & 290 & 5 & 98.3 \\
\hline Carey† & 347 & 3 & 99.1 & 53 & 6 & 88.7 & 400 & 9 & 97.8 \\
\hline Chalmers $\ddagger$ & 415 & 5 & 98.8 & 112 & 8 & 92.9 & 527 & 13 & 97.5 \\
\hline Dihmisł & 469 & 4 & 99.1 & 98 & 4 & 95.9 & 567 & 8 & 98.6 \\
\hline Duncan* & 379 & 1 & 99.7 & 69 & 1 & 98.6 & 448 & 2 & 99.6 \\
\hline Fabrił & 252 & 6 & 97.6 & 56 & 2 & 96.4 & 308 & 8 & 97.4 \\
\hline Griffithsł & 230 & 3 & 98.7 & 63 & 8 & 87.3 & 293 & 11 & 96.2 \\
\hline Grotte§ & 311 & 5 & 98.4 & 51 & 2 & 96.1 & 362 & 7 & 98.1 \\
\hline Hasan§ & 349 & 1 & 99.7 & 64 & 1 & 98.4 & 413 & 2 & 99.5 \\
\hline Hooper† & 247 & 1 & 99.6 & 19 & 0 & 100 & 266 & 1 & 99.6 \\
\hline Jones† & 191 & 1 & 99.5 & 48 & 2 & 95.8 & 239 & 3 & 98.7 \\
\hline Keenan§ & 275 & 3 & 98.9 & 53 & 3 & 94.3 & 328 & 6 & 98.2 \\
\hline McLaughlin§ & 36 & 0 & 100 & 5 & 0 & 100 & 41 & 0 & 100 \\
\hline Medirattał & 412 & 4 & 99 & 76 & 4 & 94.7 & 488 & 8 & 98.4 \\
\hline Millner* & 419 & 5 & 98.8 & 84 & 6 & 92.9 & 503 & 11 & 97.8 \\
\hline Odom§ & 286 & 5 & 98.3 & 51 & 4 & 92.2 & 337 & 9 & 97.3 \\
\hline$\overline{00 \ddagger}$ & 149 & 2 & 98.7 & 48 & 5 & 89.6 & 197 & 7 & 96.4 \\
\hline Prendergast§ & 375 & 7 & 98.1 & 63 & 7 & 88.9 & 438 & 14 & 96.8 \\
\hline Pullan & 406 & 3 & 99.3 & 107 & 5 & 95.3 & 513 & 8 & 98.4 \\
\hline Rashid $\ddagger$ & 290 & 5 & 98.3 & 81 & 4 & 95.1 & 371 & 9 & 97.6 \\
\hline Sogliani* & 229 & 1 & 99.6 & 51 & 0 & 100 & 280 & 1 & 99.6 \\
\hline Waterworth† & 330 & 4 & 98.8 & 56 & 2 & 96.4 & 386 & 6 & 98.4 \\
\hline Yonan† & 323 & 2 & 99.4 & 65 & 1 & 98.5 & 388 & 3 & 99.2 \\
\hline
\end{tabular}

*Blackpool Victoria Hospital.

†South Manchester Universities Hospitals Trust.

+Cardiothoracic Centre Liverpool.

\$Manchester Heart Centre. 
Table 2 Outcome for isolated first time aortic valve replacement (AVR) with survival rounded to nearest integer. Mortality for all surgeons falls below the $99 \%$ upper control limit of national mortality for crude data, and thus indicates satisfactory performance

\begin{tabular}{|c|c|c|c|c|c|c|c|c|c|}
\hline \multirow[b]{2}{*}{ Surgeon } & \multicolumn{3}{|c|}{ Low risk isolated AVR } & \multicolumn{3}{|c|}{ High risk isolated AVR } & \multicolumn{3}{|c|}{ All isolated AVR } \\
\hline & Cases & Deaths & $\%$ survival & Cases & Deaths & $\%$ survival & Cases & Deaths & \% survival \\
\hline $\mathrm{Au}^{*}$ & 23 & 1 & 96 & 15 & 0 & 100 & 38 & 1 & 97 \\
\hline Bridgewater† & 14 & 0 & 100 & 27 & 1 & 96 & 41 & 1 & 98 \\
\hline Campbell† & 17 & 0 & 100 & 16 & 1 & 94 & 32 & 1 & 97 \\
\hline Carey† & 16 & 0 & 100 & 21 & 0 & 100 & 37 & 0 & 100 \\
\hline Chalmersł & 17 & 0 & 100 & 22 & 0 & 100 & 39 & 0 & 100 \\
\hline Dihmis $\ddagger$ & 25 & 0 & 100 & 33 & 0 & 100 & 58 & 0 & 100 \\
\hline Duncan* & 30 & 0 & 100 & 24 & 1 & 96 & 54 & 1 & 98 \\
\hline Fabrił & 33 & 0 & 100 & 33 & 1 & 97 & 66 & 1 & 98 \\
\hline Griffithsł & 12 & 0 & 100 & 22 & 0 & 100 & 34 & 0 & 100 \\
\hline Grotte§ & 27 & 0 & 100 & 26 & 0 & 100 & 53 & 0 & 100 \\
\hline Hasan§ & 41 & 0 & 100 & 23 & 1 & 96 & 64 & 1 & 98 \\
\hline Hooper† & 32 & 0 & 100 & 26 & 1 & 96 & 58 & 1 & 98 \\
\hline Jones† & 16 & 1 & 94 & 14 & 1 & 93 & 30 & 2 & 93 \\
\hline Keenan§ & 22 & 0 & 100 & 19 & 0 & 100 & 41 & 0 & 100 \\
\hline McLaughlin§ & 2 & 0 & 100 & 1 & 0 & 100 & 3 & 0 & 100 \\
\hline Medirattał & 23 & 0 & 100 & 29 & 5 & 83 & 52 & 5 & 90 \\
\hline Millner* & 29 & 1 & 97 & 26 & 1 & 96 & 55 & 2 & 96 \\
\hline Odom§ & 35 & 0 & 100 & 17 & 1 & 94 & 52 & 1 & 98 \\
\hline $00 \ddagger$ & 8 & 0 & 100 & 14 & 1 & 93 & 22 & 1 & 96 \\
\hline Prendergast§ & 29 & 1 & 97 & 21 & 0 & 100 & 50 & 1 & 98 \\
\hline Pullanf & 21 & 0 & 100 & 28 & 0 & 100 & 49 & 0 & 100 \\
\hline Rashidf & 22 & 0 & 100 & 49 & 0 & 100 & 71 & 0 & 100 \\
\hline Sogliani* $^{\star}$ & 4 & 0 & 100 & 4 & 1 & 75 & 8 & 1 & 88 \\
\hline Waterworth† & 32 & 0 & 100 & 27 & 0 & 100 & 59 & 0 & 100 \\
\hline Yonant & 16 & 0 & 100 & 15 & 1 & 93 & 31 & 1 & 97 \\
\hline
\end{tabular}

*Blackpool Victoria Hospital.

†South Manchester Universities Hospitals Trust.

¥Cardiothoracic Centre Liverpool.

$\S$ Manchester Heart Centre.

nary artery bypass surgery and 44 (3-71) for aortic valve replacement. These differences reflect several issues, including date of the consultant's appointment, the nature of the individual's surgical practice (pure cardiac or combined cardiothoracic), subspecialist skill, referral patterns, and other commitments such as management and research. Seventeen per cent (range 7-24\% between surgeons) of the patients undergoing coronary artery surgery and half (33-69\%) of those undergoing aortic valve surgery were considered high risk. Again these variations reflect many variables, including referral patterns, perceived skill, and the surgeon's threshold for accepting high risk cases. For all isolated surgery the mortality was $1.8 \%$ (range $0-3.2 \%$ ) for coronary artery surgery and $1.9 \%(0-12 \%)$ for aortic valve replacement. For low risk patients the overall mortality was $1 \%$ $(0-2.4 \%)$ for coronary artery surgery was and $0.9 \%(0 \%$ to $6 \%$ ) for aortic valve replacement.

Figures 1 and 2 show the number of cases and mortality for the two operations. We compared mortality outcomes with published national data for the United Kingdom. In 2002-3 the numbers were 2.0\% for coronary artery surgery and 3.2\% for aortic valve replacement. ${ }^{2}$ The figures also show $99 \%$ control limits as a funnel plot. ${ }^{12}$ For all surgeons, mortality fell within the limits, suggesting satisfactory performance.

\section{Discussion}

\section{Principal findings}

We have presented mortality data for named surgeons for isolated first time coronary artery surgery and isolated first time aortic valve surgery for all surgeons operating in north west England in 2001-4. We subdi- vided the patients into low and high risk groups. Members of the public can now see the outcomes of these individual surgeons and can be reassured that all are performing to satisfactory standards. This type of analysis will become increasingly common under the Freedom of Information Act.

\section{Strengths and weaknesses}

We carried out this study on a dataset produced from all patients undergoing cardiac surgery in north west England over a three year period. These data have been validated locally and have the confidence of clinicians, but they have not been subjected to external validation. It is essential to stratify outcomes by risk to be fair to surgeons and prevent risk averse behaviour. Outcomes are influenced by "the socioeconomic status of the local population; severity of cardiac illness;

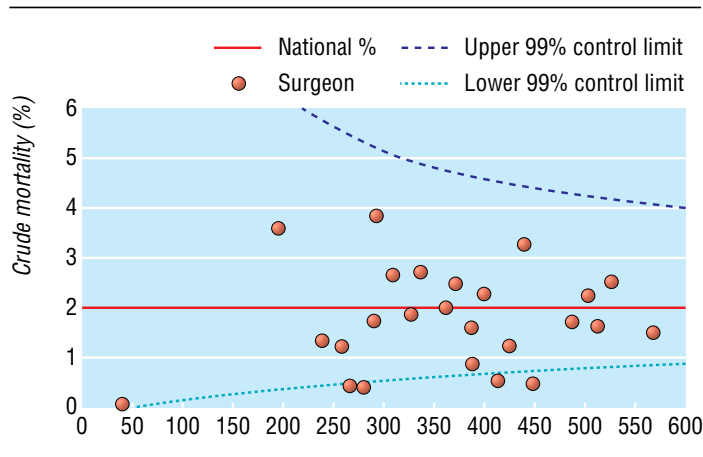

No of cases

Fig 1 Funnel plot of mortality against national data for CABG, showing mortality for each surgeon and $99 \%$ control limits 




Fig 2 Funnel plot of mortality against national data for AVR, showing mortality for each surgeon and $99 \%$ control limits

prevalence of co-morbidities; threshold of referral from both the general practitioner and the cardiologist; threshold of acceptance by the surgeon; standards of anaesthesia, surgery and intensive care; adequacy of the facilities and staffing levels; attitude to training; interpersonal relationships between staff; and the geographical layout of the unit." As the surgeon is only one of these factors, albeit an important one, we have some reservations about publishing data for named surgeons. It does, however, seem to be what the public wants and was recommended by the Bristol Royal Infirmary inquiry. ${ }^{1}$ As surgeons are important in institutional change ${ }^{13}$ this type of analysis is useful as it could stimulate improvements in systems of care as well as reassure the public, as long as it does not lead to denial of surgery to higher risk patients. ${ }^{6}$

We included in our analysis all patients undergoing surgery in NHS hospitals. During the study period, several low risk NHS patients were operated on by the same surgeons listed in this analysis in private hospitals under waiting list initiative schemes and have not been included in the results. This was seen to differing extents in the four hospitals and potentially skews the results. Similarly, there were differing rates of private patients (who are usually low risk) undergoing surgery within the NHS hospitals, which is a further potentially confounding factor.

The volume of patients undergoing coronary artery surgery was large, with an average of 363 per surgeon over the three years, allowing for meaningful comparisons to be made. The number of aortic valve replacements per surgeon was much smaller. We included these data to be open and transparent about our results but because of the small numbers involved, this study has only limited power to detect any potentially outlying performance for aortic valve surgery.

\section{Comparison with other studies}

There is a precedent for publishing data on named surgeons, with programmes in place in Pennsylvania, New Jersey, and New York. In New York data are validated so comprehensively that they are some three years out of date by the time they are published. The New York system produces a risk adjusted mortality for each surgeon, rather than the risk stratified approach we have taken, and has been criticised for encouraging risk averse behaviour. ${ }^{26}$ While there is some disagreement as to what extent publishing named surgeon data actually leads to denial of surgery to high risk patients ${ }^{14}$ our belief from experience and discussion with cardiology colleagues is that it is a serious clinical concern that is potentially damaging to the public. Our analysis should help to moderate the consequence of publishing outcomes for individual surgeons.

We have used the additive EuroSCORE to divide patients into low and high risk groups. ${ }^{9}{ }^{10}$ Most patients undergoing coronary artery surgery are low risk but of all patients undergoing this operation half of the deaths are in the high risk patients. ${ }^{9}$ We have also shown that, while the EuroSCORE is a useful overall tool for risk prediction, it is not reliable at adjusting for risk in high risk patients. ${ }^{9}$ We therefore simply used the EuroSCORE to subdivide the patients into the two groups and presented the results without further adjustment. We think that this should make our analysis clear, but it is important to note that patients within the high risk cohort will be a heterogeneous group, ranging from the very elderly patient with little cardiac dysfunction and no co-morbidities (who most surgeons would consider likely to have a pretty good outcome with surgery) to others who have extensive cardiac dysfunction and severe multisystem abnormalities who will have a high mortality with or without surgery. Also included will be patients who develop severe complications during cardiac catheterisation who require cardiopulmonary resuscitation until emergency surgery is performed. These high risk patients are often those who have the most to gain from successful surgery and a small number of operative deaths in this group could adversely affect a surgeon's results but in no way be a result of poor operative care. Because of the varied nature of high risk patients and the limitations of existing risk adjustment models, we would urge caution is the comparison of outcomes between surgeons in this group.

Similarly, patients considered to be low risk are not completely homogeneous. Surgeons may regard as high risk some patients categorised as low risk by EuroSCORE-for example, those with very severe diffuse calcified coronary artery disease in the absence of other risk factors, or previously fit patients undergoing surgery with ongoing chest pain after an acute coronary syndrome. Again a small number of fatalities in these patients, which may be due to no surgical fault, might easily distort the results.

The cut off for risk adjustment was based on previous analyses of isolated coronary artery surgery. ${ }^{910} \mathrm{We}$ used a similar cut off for our analysis of aortic valve surgery (EuroSCORE $\leq 5$ ). The mortality in the low risk groups was similar for both operations, but half of the patients undergoing aortic valve surgery were high risk compared with $17 \%$ of patients undergoing coronary artery surgery. This may simply reflect that aortic valve surgery overall carries a greater risk than coronary artery surgery but may also reflect limitations in the risk adjustment methods, which will require further investigation.

We have presented the data in funnel plots ${ }^{12}$ comparing mortality for each surgeon with the national mean for that operation. ${ }^{2}$ We benchmarked ourselves against national data, and, in the absence of risk stratified data to use for comparison, we had to use crude mortality. All surgeons' mortality in this study fell below the $99 \%$ prediction interval of the national mean. This level seemed appropriate given the 
number of surgeons in the study and the relatively small number of operations each surgeon had performed to try to balance the risks of missing unacceptable performance and the chance of wrongly labelling the performance of a good surgeon as unacceptable.

\section{Implications}

This study will inform the public about outcome data for individual surgeons. The overall analysis shows that results in north west England are good and no surgeon shows unacceptable performance for either operation. The results compare favourably with national and international data. ${ }^{2}$ Patients in north west England will now be able to scrutinise an individual surgeon's comparative outcomes, and this should provide reassurance about overall quality and give the ability to exercise choice of surgeon. As data for all surgeons fall within predefined limits on a funnel plot, however, we would argue that there would be little basis for using the data presented here to select one, rather than another, surgeon in this list. This type of analysis should be updated regularly to give ongoing reassurance to patients and should be fed into local systems of surgeon appraisal and national programmes for professional revalidation.

\section{Unanswered questions and future research}

There has been considerable attention placed on results in cardiac surgery but so far these have not been explicit on a named surgeon basis in the United Kingdom. The implications for patients and doctors of the type of analysis presented here are not fully understood and will warrant further investigation. The Society of Cardiothoracic Surgeons will soon have a full dataset on all patients undergoing surgery in Great Britain and Ireland, and a complete analysis with results for all surgeons may prove useful. Medical and surgical specialties with less well evolved data collection systems and techniques of risk adjustment are still subject to disclosure of outcome data for named clinicians under the Freedom of Information Act, and the implications of this on patients and the medical profession are not yet clear.

The named consultant surgeons were operating at the end of March 2004 in north west England. All analyses were undertaken at the Cardiothoracic Centre Liverpool. The surgical steering group of the programme comprises John $\mathrm{Au}$, Ben Bridgewater, Brian Fabri, Antony Grayson, Geir Grotte, Mark Jackson, Mark Jones, Danny Keenan, and Russell Millner. We thank the audit officers working in each centre for their hard work in collecting and validating the data. All the named surgeons approved this paper.

Contributors: This study was conducted on behalf of all cardiac surgeons in north west England. BB was responsible for study design and prepared the manuscript with Antony Grayson. AG and Mark Jackson performed the analysis. All surgeons reviewed the manuscript and contributed to its final draft. BB is guarantor.

Funding: Funding for the north west quality improvement programme in cardiac interventions collaboration has been received from all primary care trusts in north west England. All involved with this study were independent from the funding.

Competing interests: John Au, Ben Bridgewater, Brian Fabri, Antony Grayson, Geir Grotte, Mark Jackson, Mark Jones, Danny Keenan, and Russell Millner are members of the steering group of the NWQIP. BB is a member of the tripartite group (Department of Health, Healthcare Commission, and Society of Cardiothoracic Surgeons of GB and Ireland), responsible for steering national cardiac surgery audit in England and Wales.

\section{What is already known on this topic}

Analysis of crude postoperative mortality associated with isolated first time coronary artery surgery suggests that all surgeons currently operating in the United Kingom are achieving predefined standards

Actual mortality data for individual surgeons has not been published on a national or regional basis

Publication of mortality data that have not been adjusted for risk has been criticised as being unfair to surgeons and for encouraging surgeons to turn down high risk cases

\section{What this study adds}

Mortality associated with isolated first time coronary artery surgery and isolated first time aortic valve replacement for low and high risk patients in one area in England has been shown for named surgeons

The overall results are good and all surgeons perform to satisfactory standards

Use of this type of analysis should help to prevent risk averse behaviour by surgeons and promote a culture of openness and transparency in healthcare delivery

Ethical approval: The north west quality improvement programme was approved by the regional ethical committee.

Learning from Bristol: the report of the public inquiry into children's heart sur gery at the Bristol Royal Infirmary 1984-1995. www.bristol-inquiry.org.uk (accessed 26 Jan 2004).

Keogh BE, Kinsman R. Fifth national adult cardiac surgical database report 2003. Henley on Thames: Dendrite Clinical Systems, 2004.

Keogh B, Spiegelhalter D, Bailey A, Roxburgh J, Magee P, Hilton C. The legacy of Bristol: public disclosure of individual surgeons' results. BMJ 2004;329:450-4.

4 Shipman Inquiry. Fifth report: safeguarding patients: lessons from the past-proposals for the future. www.the-shipman-inquiry.org.uk/ fifthreportasp (accessed 26 Jan 2004).

5 Blackstone EH. Monitoring surgical performance. J Thorac Cardiovasc Surg 2004;128:807-10.

6 Burack JH, Impellizzeri P, Homel P, Cunningham JN Jr. Public reporting of surgical mortality: a survey of New York State cardiothoracic surgeons. Ann Thorac Surg 1999;68:1195-2000.

7 Northwest quality improvement programme in cardiac interventions. Www. nwheartaudit.nhs.uk (accessed 26 Jan 2004).

8 Roques F, Nashef SA, Michel P, Guaducheau E, de Vincentiis C, Baudet E, et al. Risk factors and outcome in European cardiac surgery; analysis of the EuroSCORE multinational database of 19,030 patients. Eur J Cardiothorac Surg 1999;15:816-23.

9 Bridgewater B, Grayson AD, Jackson M, Brooks N, Grotte GJ, Keenan DJ, et al. Surgeon specific mortality in adult cardiac surgery: comparison between crude and risk stratified data. BMJ 2003;327:13-7.

10 Nashef SA, Roques F, Michel P, Gauducheau E, Lemeshow S, Salamon R, the EuroSCORE study group. European system for cardiac operative risk evaluation (EuroSCORE). Eur J Cardiothorac Surg 1999;16:9-13.

11 Clopper CJ, Pearson ES. The use of confidence or fiducial limits illustrated in the case of the binomial. Biometrika 1934;26:404-13.

12 Stark J, Gallivan S, Longrove J, Hamilton JR, Monro JL, Pollock, JC, et al. Mortality rates after surgery for congenital heart defects in children and surgeon's performance. Lancet 2000;355:1004-7.

13 Chassin MR. Improving the quality of care. Part 3: improving the quality of care. N Engl J Med 1996;335:1060-3.

14 Hannan EL, Siu AL, Kumar D, Racz M, Pryor DB, Chassin MR. Assessment of coronary artery bypass graft surgery performance in New York. Is there a bias against taking high-risk patients? Med Care 1997;35:49-56

(Accepted 14 February 2005) 